\title{
Effect of Body Mass Index on Posttonsillectomy Hemorrhage
}

\author{
Tetsuro Hoshino, ${ }^{1}$ Tohru Tanigawa, ${ }^{1}$ Gen Yanohara, ${ }^{1}$ Kenta Murotani, ${ }^{2}$ \\ Yuichiro Horibe, ${ }^{1}$ Toyoaki Murohara, ${ }^{3}$ Rei Shibata, ${ }^{4}$ and Hiromi Ueda ${ }^{1}$ \\ ${ }^{1}$ Department of Otolaryngology, Aichi Medical University, Aichi, Japan \\ ${ }^{2}$ Division of Biostatistics, Clinical Research Center, Aichi Medical University, Aichi, Japan \\ ${ }^{3}$ Department of Cardiology, Nagoya University Graduate School of Medicine, Nagoya, Japan \\ ${ }^{4}$ Department of Advanced Cardiovascular Therapeutics, Nagoya University Graduate School of Medicine, Nagoya, Japan
}

Correspondence should be addressed to Tohru Tanigawa; tanigawa@aichi-med-u.ac.jp

and Rei Shibata; rshibata@med.nagoya-u.ac.jp

Received 26 January 2017; Accepted 19 March 2017; Published 7 May 2017

Academic Editor: Satoaki Matoba

Copyright (C) 2017 Tetsuro Hoshino et al. This is an open access article distributed under the Creative Commons Attribution License, which permits unrestricted use, distribution, and reproduction in any medium, provided the original work is properly cited.

Objective. Obesity affects adverse outcomes in patients undergoing various surgeries. Tonsillectomy is one of the most common surgical procedures and posttonsillectomy hemorrhage $(\mathrm{PTH})$ is the major complication in patients with tonsillectomy. However, the effect of body mass index (BMI) on posttonsillectomy bleeding episodes is not well known. This study aimed to assess the clinical association between obesity and PTH. Methods. A total of 98 tonsillectomies were retrospectively reviewed. Patient charts were analyzed regarding demographic data and the indication for surgery. Patients with PTH were compared with uneventful cases. Patients were divided into three groups based on BMI: normal weight (BMI $\left.<25 \mathrm{~kg} / \mathrm{m}^{2}\right)$, overweight $\left(\mathrm{BMI} \geq 25 \mathrm{and}<30 \mathrm{~kg} / \mathrm{m}^{2}\right)$, and obese $\left(\geq 30 \mathrm{~kg} / \mathrm{m}^{2}\right)$. Results. PTH occurred in $13 \%$ of patients with normal weight, in $23.5 \%$ of patients with overweight, and in $50 \%$ patients with obesity. The occurrence of PTH was significantly higher in patients with obesity than in those with normal weight and overweight $(p=0.008)$. Multivariate analysis showed that obesity was a significant factor affecting the incidence of PTH after adjusting for confounding factors. Conclusions. Our findings suggest that the obese condition is independently associated with the incidence of PTH.

\section{Introduction}

Obesity has become a major health problem in industrial countries with an increasing prevalence in adults and children [1]. Obesity affects adverse outcomes in patients undergoing various types of surgery [2].

Tonsillectomy is one of the most common surgical procedures in the field of otorhinolaryngology. Posttonsillectomy hemorrhage (PTH) is the major complication in patients after tonsillectomy. The overall hemorrhage rate is approximately $10 \%$ [3]. Although some potential risk factors for PTH have been investigated [4-14], the effect of body mass index (BMI) on posttonsillectomy bleeding episodes in adults is not well known $[15,16]$.

In the present study, we investigated the clinical association between obesity and PTH.

\section{Materials and Methods}

2.1. Patients. We assessed 98 patients who underwent tonsillectomy at the Department of Otolaryngology, Aichi Medical University, from August 2011 through December 2013. BMI was calculated according to Quetelet $\left(\mathrm{kg} / \mathrm{m}^{2}\right)$. Patients were divided into three groups based on BMI: normal weight (BMI $<25 \mathrm{~kg} / \mathrm{m}^{2}$ ), overweight (BMI $\geq 25$ and $<30 \mathrm{~kg} / \mathrm{m}^{2}$ ), and obese $\left(\geq 30 \mathrm{~kg} / \mathrm{m}^{2}\right)$. This BMI classification system is endorsed by the World Health Organization and the National Institutes of Health. This system is the most widely accepted means of stratifying individuals based on weight [15]. Patients with hematological diseases, deteriorated immune function, chronic wasting disease, and uncontrolled chronic disease were excluded. Children $(<12$ years old) were excluded because PTH in children is less common than in older patients. 
TABLE 1: Classification of posttonsillectomy hemorrhage (PTH).

\begin{tabular}{ll}
\hline Category I & $\begin{array}{l}\text { Minimal hemorrhage, controlled after noninvasive } \\
\text { treatment }\end{array}$ \\
Category II & $\begin{array}{l}\text { Hemorrhage requiring treatment with local } \\
\text { anesthesia }\end{array}$ \\
Category III & Revision surgery under general anesthesia
\end{tabular}

2.2. Surgical Methods. Patients underwent surgery under general anesthesia with orotracheal intubation. We inserted a Boyle-Davis mouth gag with the patient in the supine position. The tonsil was removed by blunt peeling with a cotton ball [3]. Hemostasis of the tonsillar fossa was ablated using the Bayonet bipolar device (FC-100A; Daiichi Medical Co., Ltd., Tokyo, Japan). The inferior pole of the tonsil was ablated in all cases and the tonsil was completely removed under direct vision. If surgeons decided that ligation was necessary, ligatures were added using silk. We completed the operation after complete hemostasis of both tonsillar fossae was achieved. Patients were admitted to the hospital 1 to 3 days before surgery. Patients were usually hospitalized for 7 days after surgery. If necessary, the length of hospitalization was extended to more than 8 days after surgery.

2.3. Definition of Posttonsillectomy Hemorrhage. We defined PTH as any hemorrhagic episode after extubation. PTH was categorized according to the severity of the hemorrhagic episode as follows: (I) minimal hemorrhage that was controlled after noninvasive treatment, (II) hemorrhage requiring treatment with local anesthesia, and (III) hemorrhage requiring revision surgery under general anesthesia (Table 1) [3]. The period since tonsillectomy to PTH was also recorded.

2.4. Statistical Analysis. The effect of 10 factors (BMI, sex, age, indication, tonsil size, platelet count, activated partial thromboplastin time, surgeon's experience, blood loss, and with or without ligation) on PTH was evaluated using Fisher's extract test or the Wilcoxon rank sum test. Variables with $p<$ 0.05 in univariate analysis were incorporated into the multivariable model. All statistical analyses were performed using SAS 9.4 (SAS Institute Inc., Cary, NC, USA). A $p$ value of $<0.05$ was considered statistically significant. The study protocol was approved by the Ethics Review Committee of our hospital.

\section{Results}

3.1. Baseline Characteristics. PTH occurred in 19 of 98 (19.4\%) patients. PTH occurred most frequently on postoperative days 6 and 7 ( 4 and 5 patients, resp.). Category III PTH (reoperation under general anesthesia) was observed in three (3.1\%) patients. All cases of PTH occurred within 12 days after tonsillectomy (Figure 1).

The occurrence rate of PTH in male patients was significantly higher than that in female patients (Table 2, $p=0.040$ ). The mean age in patients with or without PTH was 33.4 years and 32.6 years, respectively. Age did not affect the occurrence of PTH. PTH was observed in none of 55 (16.4\%) patients

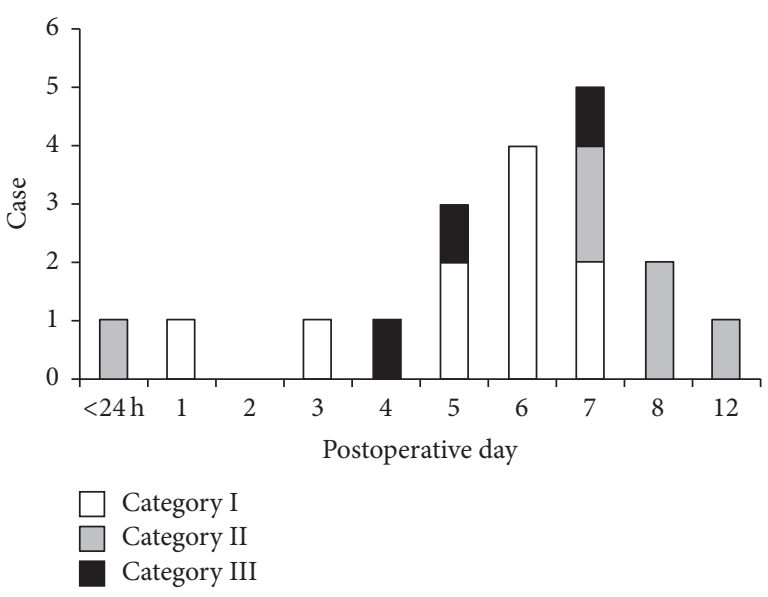

Figure 1: Posttonsillectomy hemorrhage: posttonsillectomy hemorrhage (PTH) was observed in 19 (19.4\%) patients. Of these 19 patients, one (5.3\%) had primary hemorrhage and 18 (94.7\%) had secondary hemorrhage. All PTH episodes occurred within 12 days after tonsillectomy. PTH episodes occurred most frequently on postoperative days 7 (5 patients) and 6 (4 patients). Category III PTH (reoperation under general anesthesia) was observed in three patients. Therefore, the overall risk of reoperation was 3.1\% (3/98).

with chronic tonsillitis, two of 21 (7.7\%) patients with $\operatorname{IgA}$ nephropathy, and eight of $23(42.1 \%)$ patients with sleep apnea syndrome (SAS). The occurrence of PTH was significantly higher in patients with SAS, but not in those with chronic tonsillitis and $\operatorname{IgA}$ nephropathy $(p=0.040)$. There were no significant differences in platelet count and activated partial thromboplastin time between patients with or without PTH. There were also no significant differences in the surgeon's experience, with or without ligation, and total blood loss between patients with or without PTH.

Normal weight was observed in $69(70.4 \%)$ patients, overweight in 17 (17.3\%), and obesity in 12 (12.2\%). PTH occurred in nine of 69 (13\%) patients with normal weight, in four of $17(23.5 \%)$ patients with overweight, and in six of 12 (50\%) patients with obesity. The occurrence rate of PTH was significantly higher in patients with obesity than in those with normal weight and overweight (Table 2, $p=0.012$ ).

3.2. Effects of Various Factors on Posttonsillectomy Hemorrhage. To determine the factors associated with the occurrence of PTH, we performed multiple logistic regression analyses. Variables with $p<0.05$ in univariate analysis were entered into multivariate logistic regression with stepwise selection. This variable selection procedure retained obstructive SAS and BMI in the final model. Table 3 shows the results of multivariate logistic regression with stepwise selection. Obesity was a significant factor that affected the incidence of PTH after adjusting for sex and etiology of obstructive SAS (odds ratio, 4.55; 95\% confidence interval, 1.10-18.8; $p=$ 0.036; Table 3).

\section{Discussion}

This study demonstrated, for the first time, that the obese condition was significantly associated with posttonsillectomy 
TABLE 2: Comparison of patients' characteristics between the PTH and non-PTH groups.

\begin{tabular}{|c|c|c|c|c|}
\hline & $\begin{array}{c}\text { Total } \\
N=98\end{array}$ & $\begin{array}{c}\text { PTH (\%) } \\
N=19 \\
\end{array}$ & $\begin{array}{c}\text { Non-PTH (\%) } \\
\quad N=79\end{array}$ & $p$ value \\
\hline Sex & & & & 0.040 \\
\hline Male & 56 & $15(26.8)$ & $41(73.2)$ & \\
\hline Female & 42 & $4(9.5)$ & $38(90.5)$ & \\
\hline Age (y) & $32.7 \pm 13.5$ & $33.4 \pm 16.6$ & $32.6 \pm 12.7$ & 0.986 \\
\hline Indication & & & & 0.040 \\
\hline Chronic tonsillitis & 55 & $9(16.4)$ & $46(83.6)$ & \\
\hline IgA nephropathy & 23 & $2(8.7)$ & $21(91.3)$ & \\
\hline OSAS & 19 & $8(42.1)$ & $11(57.9)$ & \\
\hline Benign tumor suspected & 1 & 0 & $1(100)$ & \\
\hline Tonsil size & & & & 0.444 \\
\hline I & 51 & $8(15.7)$ & $43(84.3)$ & \\
\hline II or III & 47 & $11(23.4)$ & $36(76.6)$ & \\
\hline Platelet count $\left(\times 10^{4}\right)$ & $25.4 \pm 5.3$ & $25.2 \pm 3.7$ & $25.5 \pm 5.6$ & 0.857 \\
\hline APTT & $28.5 \pm 2.8$ & $29.3 \pm 3.3$ & $28.4 \pm 2.7$ & 0.207 \\
\hline Surgeon's experience (y) & $2.0 \pm 1.2$ & $1.8 \pm 1.2$ & $2.1 \pm 1.2$ & 0.520 \\
\hline Blood loss (mL) & $12.3 \pm 20.3$ & $10.1 \pm 13.6$ & $12.8 \pm 21.6$ & 0.692 \\
\hline Ligation & & & & 1.000 \\
\hline With & 57 & $11(19.3)$ & $46(80.7)$ & \\
\hline Without & 41 & $8(19.5)$ & $33(80.5)$ & \\
\hline BMI $\left(\mathrm{kg} / \mathrm{m}^{2}\right)$ & & & & 0.012 \\
\hline $\mathrm{BMI}<25$ & 69 & $9(13.0)$ & $60(87.0)$ & \\
\hline $\mathrm{BMI} \geq 25$ and $<30$ & 17 & $4(23.5)$ & $13(76.5)$ & \\
\hline $\mathrm{BMI} \geq 30$ & 12 & $6(50)$ & $6(50)$ & \\
\hline
\end{tabular}

PTH: posttonsillectomy hemorrhage, IgA: immunoglobulin A, OSAS: obstructive sleep apnea syndrome, APTT: activated partial thromboplastin time, and BMI: body mass index.

TABLE 3: Results of multivariate logistic regression with stepwise selection.

\begin{tabular}{lcccc}
\hline Variable & Category & OR & $95 \%$ CI & $0.93-10.3$ \\
OSAS & & 3.09 & & \\
& $\mathrm{BMI}<25$ & 1 & 0.066 \\
BMI & $\mathrm{BMI} \geq 25$ and $<30$ & 1.65 & $0.42-6.54$ & 0.474 \\
& $\mathrm{BMI} \geq 30$ & 4.55 & $1.10-18.8$ & 0.036 \\
\hline
\end{tabular}

bleeding episodes in adolescents and adults. Our data suggest that patients with obesity who undergo tonsillectomy should be carefully followed up after the operation. Our findings have several implications for informed consent of patients who intend to undergo tonsillectomy. If patients are in the state of obesity before tonsillectomy, patients should reduce weight until surgery. Surgeons should be aware of frequent hemorrhage in obese patients and prepare for sudden bleeding.

Obesity affects wound healing, wound infection rate, and bleeding risk following various interventions [2, 17]. In addition, there are concerns about patients with obesity regarding the technical difficulty in performing tonsillectomy [18]. Obesity disturbs hemostasis because a wide operating field cannot be obtained because of abundant visceral fat. Therefore, wound issues and technical difficulty might cause a high rate of occurrence of PTH in patients with obesity.
Our study showed that obesity was significantly associated with posttonsillectomy bleeding episodes. In contrast to this finding, a previous report showed that overweight or obesity did not increase the risk for PTH [15]. The reason for this discrepancy between studies is unclear. A possible reason for the difference between studies is the difference in criteria for patients' inclusion. Our study was only conducted in Japanese patients who were 12 years or older. Another possible reason is due to the difference of indications for tonsillectomy. We had undergone elective tonsillectomy in all cases, whereas Riechelmann et al. performed abscess tonsillectomy in 65 of 300 patients $(21.7 \%)$. The risk of bleeding following abscess tonsillectomy seems higher than that in elective tonsillectomy [19].

In conclusion, our findings suggest that the obese condition in adolescents and adults is independently associated with the incidence of PTH. Therefore, nutritional approaches 
aimed at reducing body weight before tonsillectomy could be useful for an uncomplicated postoperative course.

\section{Conflicts of Interest}

The authors declared no conflicts of interest.

\section{Authors' Contributions}

Tetsuro Hoshino, Rei Shibata, Tohru Tanigawa, Toyoaki Murohara, and Hiromi Ueda designed and carried out the studies. Tetsuro Hoshino, Gen Yanohara, Kenta Murotani, Yuichiro Horibe, and Tohru Tanigawa analyzed the data. Tohru Tanigawa and Rei Shibata wrote the paper.

\section{References}

[1] R. Shibata, N. Ouchi, R. Takahashi et al., "Omentin as a novel biomarker of metabolic risk factors," Diabetology and Metabolic Syndrome, vol. 4, no. 1, article 37, 2012.

[2] N. J. O. Birkmeyer, D. C. Charlesworth, F. Hernandez et al., "Obesity and risk of adverse outcomes associated with coronary artery bypass surgery," Circulation, vol. 97, no. 17, pp. 1689-1694, 1998.

[3] R. Ikoma, S. Sakane, K. Niwa, S. Kanetaka, T. Kawano, and N. Oridate, "Risk factors for post-tonsillectomy hemorrhage," Auris Nasus Larynx, vol. 41, no. 4, pp. 376-379, 2014.

[4] C. Arnoldner, M. C. Grasl, D. Thurnher et al., "Surgical revision of hemorrhage in 8388 patients after cold-steel adenotonsillectomies," Wiener Klinische Wochenschrift, vol. 120, no. 11-12, pp. 336-342, 2008.

[5] M. K. Kim, J. W. Lee, M. G. Kim, S. Y. Ha, J. S. Lee, and S. G. Yeo, "Analysis of prognostic factors for postoperative bleeding after tonsillectomy," European Archives of Oto-Rhino-Laryngology, vol. 269, no. 3, pp. 977-981, 2012.

[6] K. J. Kværner, "Benchmarking surgery: secondary post-tonsillectomy hemorrhage 1999-2005," Acta Oto-Laryngologica, vol. 129, no. 2, pp. 195-198, 2009.

[7] J. N. Perkins, C. Liang, D. Gao, L. Shultz, and N. R. Friedman, "Risk of post-tonsillectomy hemorrhage by clinical diagnosis," The Laryngoscope, vol. 122, no. 10, pp. 2311-2315, 2012.

[8] S. Sarny, W. Habermann, G. Ossimitz, and H. Stammberger, "Significant post-tonsillectomy pain is associated with increased risk of hemorrhage," Annals of Otology, Rhinology and Laryngology, vol. 121, no. 12, pp. 776-781, 2012.

[9] S. Sarny, G. Ossimitz, W. Habermann, and H. Stammberger, "Hemorrhage following tonsil surgery: a multicenter prospective study," Laryngoscope, vol. 121, no. 12, pp. 2553-2560, 2011.

[10] S. Sarny, W. Habermann, G. Ossimitz, C. Schmid, and H. Stammberger, "Tonsilar haemorrhage and re-admission: a questionnaire based study," European Archives of Oto-Rhino-Laryngology, vol. 268, no. 12, pp. 1803-1807, 2011.

[11] S. Sarny, G. Ossimitz, W. Habermann, and H. Stammberger, "Preoperative coagulation screening prior to tonsillectomy in adults: current practice and recommendations," European Archives of Oto-Rhino-Laryngology, vol. 270, no. 3, pp. 10991104, 2013.

[12] T. A. Tami, G. S. Parker, and R. E. Taylor, "Post-tonsillectomy bleeding: an evaluation of risk factors," Laryngoscope, vol. 97, no. 11, pp. 1307-1311, 1987.
[13] H. K. Tolska, A. Takala, J. Pitkäniemi, and J. Jero, "Post-tonsillectomy haemorrhage more common than previously described-an institutional chart review," Acta Oto-Laryngologica, vol. 133, no. 2, pp. 181-186, 2013.

[14] A. Tomkinson, W. Harrison, D. Owens, S. Harris, V. McClure, and M. Temple, "Risk factors for postoperative hemorrhage following tonsillectomy," Laryngoscope, vol. 121, no. 2, pp. 279288, 2011.

[15] H. Riechelmann, E. C. Blassnigg, C. Profanter, K. Greier, F. Kral, and B. Bender, "No association between obesity and posttonsillectomy haemorrhage," Journal of Laryngology and Otology, vol. 128, no. 5, pp. 463-467, 2014.

[16] A. Schrock, T. Send, L. Heukamp, A. O. Gerstner, F. Bootz, and M. Jakob, "The role of histology and other risk factors for posttonsillectomy haemorrhage," European Archives of Oto-RhinoLaryngology, vol. 266, no. 12, pp. 1983-1987, 2009.

[17] S. L. Doyle, J. Lysaght, and J. V. Reynolds, "Obesity and postoperative complications in patients undergoing non-bariatric surgery," Obesity Reviews, vol. 11, no. 12, pp. 875-886, 2010.

[18] R. Ishida, S. Nakamura, T. Fuke, and H. Yamada, "Post-tonsillectomy hemorrhage: a retrospective study of 503 operations," Practica Oto-Rhino-Laryngologica, vol. 99, no. 5, pp. 391-395, 2006.

[19] R. Giger, B. N. Landis, and P. Dulguerov, "Hemorrhage risk after quinsy tonsillectomy," Otolaryngology-Head and Neck Surgery, vol. 133, no. 5, pp. 729-734, 2005. 


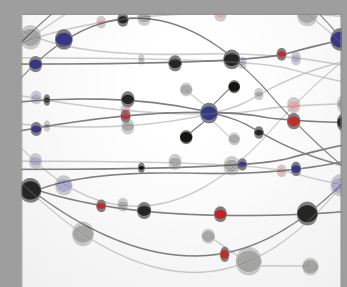

The Scientific World Journal
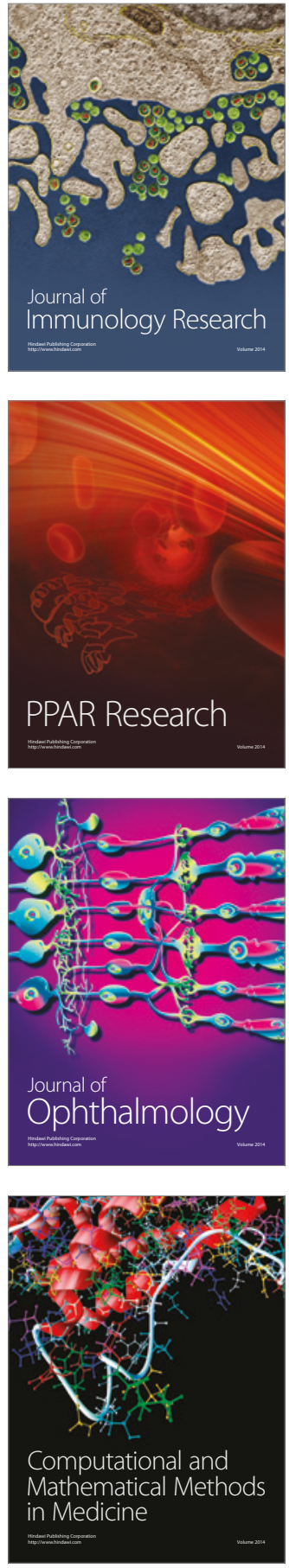

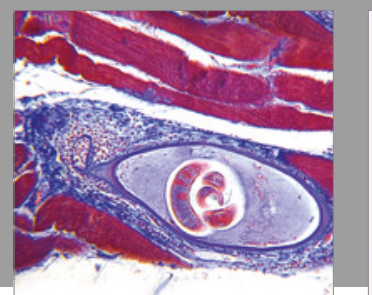

Gastroenterology Research and Practice
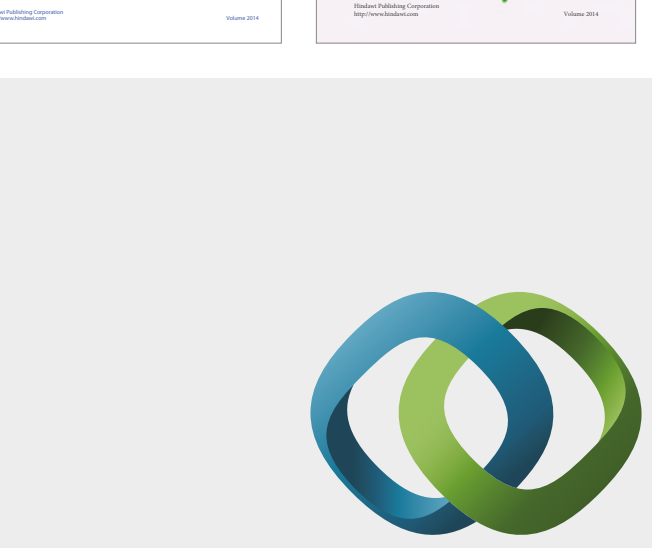

\section{Hindawi}

Submit your manuscripts at

https://www.hindawi.com
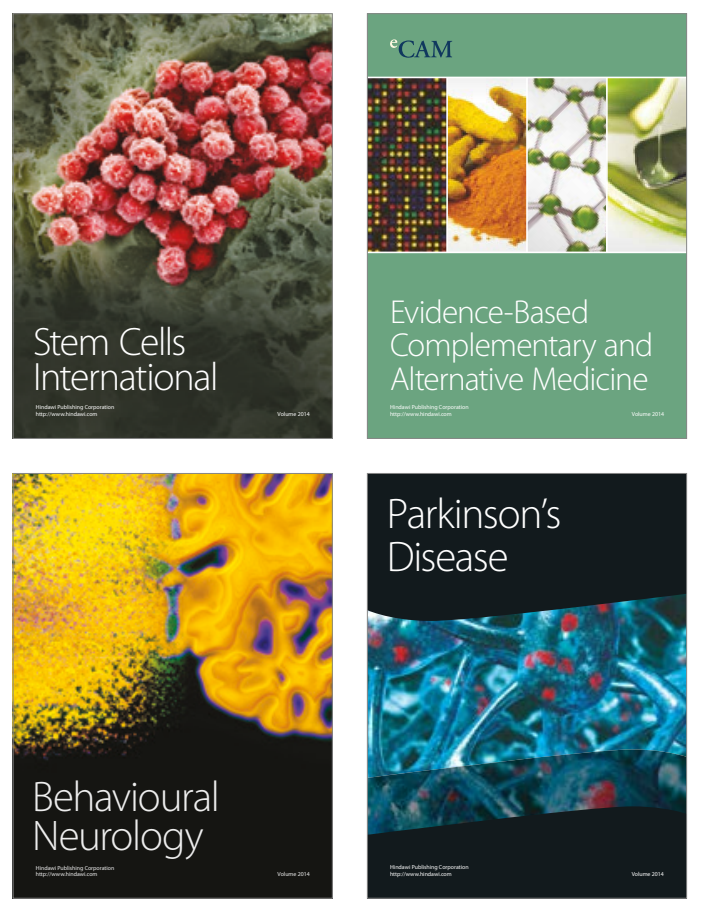
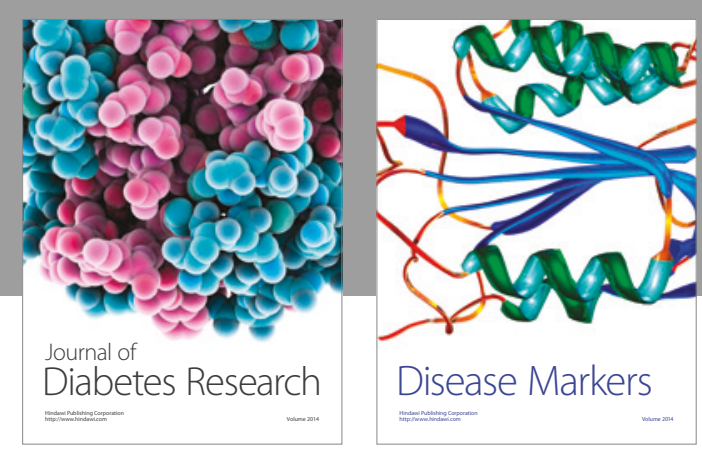

Disease Markers
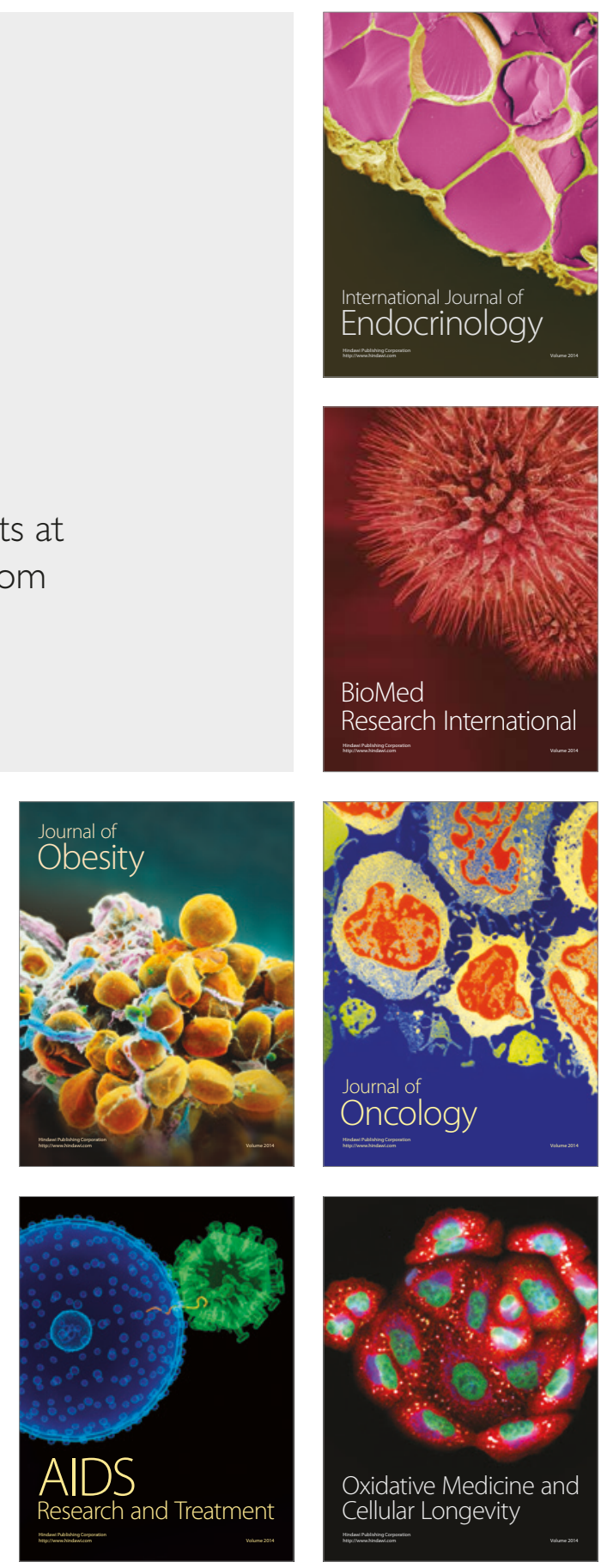